\title{
The effect of postoperative anticoagulation on false lumen patency after surgery for acute type A aortic dissection
}

\author{
Mårten Larsson ${ }^{1^{*}} \mathbb{D}$, Gracijela Bozovic ${ }^{2}$, Johan Sjögren ${ }^{1}$, Igor Zindovic ${ }^{1}$, Sigurdur Ragnarsson ${ }^{1}$ and \\ Shahab Nozohoor ${ }^{1}$
}

\begin{abstract}
Background: Patent false lumen has been shown to have a negative impact on prognosis after surgery for acute type A aortic dissection (ATAAD). We aimed to assess the effect of postoperative anticoagulation on false lumen patency and clinical outcomes in relation to false lumen status.

Methods: Postoperative computed tomographies of 156 patients undergoing ATAAD DeBakey type I surgery were retrospectively evaluated for false lumen patency. The patients were divided into groups determined by anticoagulation treatment at discharge. Uni- and multivariable logistic regression was used for analysing the effect of anticoagulation on the false lumen, and Kaplan-Meier estimates were used to assess the association of a patent false lumen with the incidence of reoperation and long-term survival.

Results: A patent false lumen was present in $81 \%$ of the patients. Postoperative anticoagulants were not associated with a patent false lumen $(p=0.48)$ in univariable analysis. In multivariable analysis, both hemiarch replacement (OR 0.15, Cl95\% 0.05-0.49, $p=0.001$ ) and the use of betablockers had a protective effect (OR 0.29, Cl95\% 0.10-0.85, $p=0.023$ ). The Kaplan-Meier estimates for survival and the composite endpoint of survival and freedom from distal reintervention indicated no difference in outcome between patients in regard to anticoagulation treatment (survival $p=0.43$, composite $p=0.82$ ) or false lumen status (survival $p=0.21$, composite $p=0.09$ ).

Conclusion: This study could not show negative effects from the postoperative use of anticoagulants on false lumen status, nor that false lumen patency was associated with poorer prognosis. A hemiarch procedure was shown to be associated with reduced risk of false lumen patency.
\end{abstract}

Keywords: Aortic dissection, False lumen, Anticoagulation

\section{Introduction}

Acute type A aortic dissection (ATAAD) requires emergent surgical repair primarily to prevent ascending aortic rupture, cardiac tamponade, acute aortic valve insufficiency with consequent ventricular dysfunction,

\footnotetext{
*Correspondence: marten.larsson@med.lu.se

${ }^{1}$ Department of Clinical Sciences Lund, Cardiothoracic Surgery, Lund University and Skåne University Hospital, Getingevägen 4, 22185 Lund, Sweden

Full list of author information is available at the end of the article
}

and cerebral malperfusion with associated stroke or coma. Ideally, surgical treatment reestablishes blood flow through the true lumen thereby depressurizing and decreasing the false lumen. Shrinkage and thrombosis of the false lumen, as well as remodeling of the aorta also are desirable but not always achieved. In spite of successful repair of the proximal entry tear, the true lumen may fail to adequately dilate distally. A patent false lumen has been shown to be associated with an increased risk of late mortality, enlargement of the remaining aorta, and original author(s) and the source, provide a link to the Creative Commons licence, and indicate if changes were made. The images or other third party material in this article are included in the article's Creative Commons licence, unless indicated otherwise in a credit line to the material. If material is not included in the article's Creative Commons licence and your intended use is not permitted by statutory regulation or exceeds the permitted use, you will need to obtain permission directly from the copyright holder. To view a copy of this licence, visit http://creativecommons.org/licenses/by/4.0/. The Creative Commons Public Domain Dedication waiver (http://creativeco mmons.org/publicdomain/zero/1.0/) applies to the data made available in this article, unless otherwise stated in a credit line to the data. 
reintervention aimed at the distal aorta(1-4). In analogy, studies of type B dissection have suggested that patients with complete thrombosis of the false lumen have improved outcomes, whereas those with a patent false lumen have an increased risk of aortic enlargement and death [1-3].

Anticoagulation therapy after surgery for ATAAD is indicated if the patient has a mechanical valve implantation or atrial fibrillation. However, the use of anticoagulants could theoretically lead to lower rates of false lumen thrombus formation, one of the secondary goals of surgery. If there is a substantial risk of reoperation or death, the small risk of thromboembolism in case of atrial fibrillation might be justified. And in the setting of determining which valve to implant, the benefit of a biological valve without demand for anticoagulation might justify implantation of this valve at a lower age than normally recommended. The rate of false lumen thrombus formation in relation to anticoagulation therapy has been studied previously, and these studies indicate similar or higher rates of false lumen patency in patients using anticoagulants [4-6].

The present study aimed to evaluate if anticoagulation postoperative have an effect on false lumen patency and to study the effect of postoperative false lumen patency on survival and the rate of reintervention in patients presenting with ATAAD DeBakey type I.

\section{Methods}

This was a single centre, retrospective, observational study and included 347 patients who underwent surgery for ATAAD from January 2005 to December 2018 at the Department of Cardiothoracic Surgery, Skane University Hospital, Lund, Sweden. Pre-, peri-, and postoperative variables were prospectively collected and entered into the department's computerised database for retrospective analysis, and medical records were reviewed when necessary. Survival data was obtained from the Swedish National Board of Health and Welfare, (Socialstyrelsen, Sweden). The registry was approved by the regional ethical review board, and a waiver of informed consent for the retrospective review of medical records was granted for the registry (ref. 2015/197).

Patients who died during hospital admission or within 30 days after surgery were excluded from the analysis. The preoperative computed tomography $(\mathrm{CT})$ scans of the aorta (mostly non-ECG gated) with and without intravenous contrast enhancement of 347 patients were examined on a clinical Picture Archiving and Communication System (PACS) workstation. Intramural hematoma (IH) defined as a focal, crescent-shaped, high attenuating (6070 Hounsfield unit, HU) region in an eccentrically thickened aortic wall on a non-contrast-enhanced CT was present in 29 patients, and in four patients the distinction between IH and ATAAD was not possible to establish [7], leading to exclusion. An additional 76 patients presented with DeBakey type II ATAAD and were excluded as the false lumen can be totally resected in most cases, leaving little to no risk of false lumen patency. Of the remaining 232 patients, the postoperative CT scans performed within one year were evaluated. Another 51 patients did not have any postoperative CTs registered and were thus excluded. Finally, a cohort of 156 patients remained for assessment. The flow chart of the inclusion protocol is presented in Fig. 1. All examinations were evaluated at two separate occasions to reduce the risk of bias.

\section{Endpoints}

The primary endpoint was the association between the postoperative anticoagulation regimen and the incidence of patent false lumen one year after surgery or the last known imaging prior to or after one year. Secondary endpoints were death or the composite of death and reintervention (open or endovascular surgery to the aorta or its immediate branches $>24 \mathrm{~h}$ after initial surgery) due to a patent false lumen or anticoagulation. Anticoagulation treatment was established at discharge from hospital. Patients treated with warfarin or non-vitamin $\mathrm{K}$ antagonist oral anticoagulants (NOACs) were defined as the anticoagulation group and compared to the remaining patients constituting the control group. Major bleeding was defined based on the BART criteria with patients fulfilling any of these variables: postoperative bleeding through chest tubes exceeding $1500 \mathrm{ml}$ over any 8-h period; reoperation for bleeding or cardiac tamponade within $24 \mathrm{~h}$ of surgery; transfusion of more than $10 \mathrm{U}$ of red blood cells within $24 \mathrm{~h}$ after surgery; or death from haemorrhage within 30 days.

\section{Radiology}

The CT examinations of the aorta were performed with intravenous contrast in routine scan settings and reconstruction parameters at our institution and referring

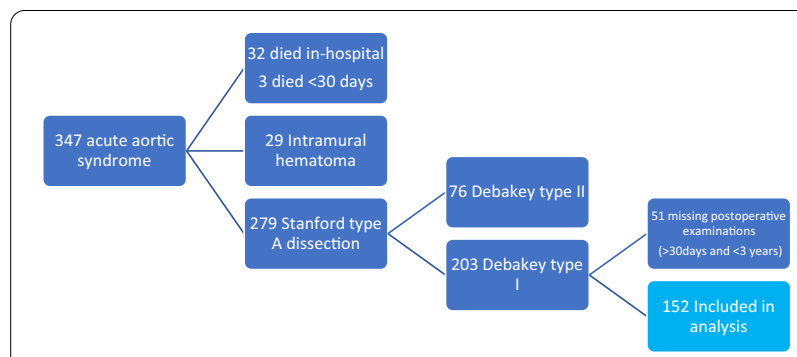

Fig. 1 Flow chart of patients with acute aortic syndromes referred to the Department of Cardiothoracic Surgery, Skåne University Hospital, Lund, during the inclusion period 
hospitals with a diverse machine park ranging from Philips Mx8000 Idt 16 to Dual Source CT Scanner, reflecting the rapid development of $\mathrm{CT}$ scanners during the study period. The images varied from $5 \mathrm{~mm}$ thick slices reconstructed in three planes to $1 \mathrm{~mm}$ source slices enabling complete reconstructions. All postoperative contrast-enhanced CT scans of the aorta within one year were evaluated for persisting false lumen [8] on a clinical PACS workstation with an appropriate window setting for the aorta [9]. False lumen was considered patent if any contrast was found outside the true lumen in the thoracic aorta. The patients were divided into three groups according to the status of their aorta. Group I patients showed no contrast outside the true lumen, group II had a patent false lumen in either ascending and/or arch (including or excluding descending aorta) and group III had a patent false lumen only in the descending aorta. All postoperative CT scans involving the chest with contrast enhancement within one year were evaluated. For patients with a limited number of examinations, the examination closest to one year with $>30$ days follow-up was chosen.

\section{Surgical procedure}

As previously described [10], surgery was performed through a median sternotomy with cardiopulmonary bypass. Deep hypothermia $\left(<20^{\circ} \mathrm{C}\right)$ and circulatory arrest was used in most cases with open distal anastomosis after inspection of the ascending aorta and the aortic arch. Cerebral protection with steroids (500 mg methylprednisolone) and a barbiturate (thiopental or phenobarbital) was used routinely in deep hypothermic arrest. In eight cases, cross-clamp was used in normothermia. After distal anastomosis was completed, distal perfusion was re-established through a side branch in the vascular prosthesis, the patient rewarmed, and the proximal aorta, valve and root inspected for tears. If deemed necessary, the valve and/or or root was replaced. When the proximal anastomosis was completed and the patient was normothermic, cardiopulmonary bypass was terminated.

\section{Follow-up}

Surgical or endovascular treatment during follow-up was considered if any of the following were observed: dissection progression with signs of impending rupture, signs of impaired visceral or peripheral perfusion, retrograde extension of the dissection to the remaining arch or ascending aorta, increasing aortic insufficiency, and aortic diameter $>55 \mathrm{~mm}$.

\section{Statistics}

Categorical data were given as proportions, and continuous variables were expressed as the mean \pm standard

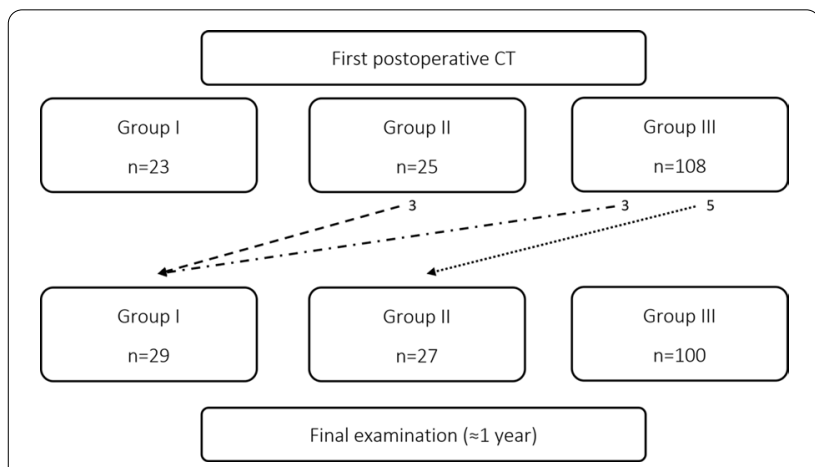

Fig. 2 Flow chart of false lumen status and change during the observation period

deviation. In skewed distributions, medians and interquartile ranges (IQRs) were reported. Proportions were compared using the chi-square test. If the expected frequency was $<5$, Fisher's exact test was applied. For continuous variables, Student's $t$-test was used. Event rates during follow-up were estimated and survival was plotted using the Kaplan-Meier method, with the differences between groups compared using the log-rank test. Uni- and multivariable logistic regression analyses were performed to determine independent predictors of patent false lumen and relied on complete cases analysis. Variables that were considered to potentially impact false lumen status and with a $p$ value $<0.1$ were fitted to a multivariable regression model. Postoperative treatment with anticoagulation was forced into the analysis. The results of logistic regression analyses are expressed as hazard ratios (HRs) and odds ratios (ORs) with 95\% confidence intervals (CI). A $p$ value $<0.05$ was considered statistically significant unless otherwise stated. Statistical analysis relied on standard software (IBM Corp. Released 2017. IBM SPSS Statistics for PC, Version 25.0.0. Armonk, NY, USA: IBM Corp.)

\section{Results}

The mean follow-up for mortality was $6.5 \pm 3.9$ years (median 5.6 years; IQR 3.2-8.3). Mean follow-up for the composite endpoint of mortality and reintervention was $5.2 \pm 3.5$ years (median 4.5 years; IQR 2.5-7.5) and mean follow-up of the last CT was $358 \pm 184$ days, (median 389 days; IQR 268-475).

A patent false lumen was present in $81 \%$ of patients $(\mathrm{n}=127 / 156)$ with $17 \%(\mathrm{n}=27)$ being categorised as group II and $64 \%(\mathrm{n}=100)$ as group III at 1-year followup. In $7 \%$ of patients $(n=10)$, the false lumen group changed during the observation period (Fig. 2). At discharge, $36 \%$ of patients $(n=56)$ received anticoagulation treatment, 18 patients were treated with NOAC, and 
Table 1 Preoperative characteristics

\begin{tabular}{llll}
\hline & $\begin{array}{l}\text { No } \\
\text { anticoagulation } \\
(\mathbf{n = 1 0 0 )}\end{array}$ & $\begin{array}{l}\text { Warfarin } \\
\text { or NOAC } \\
\mathbf{( n = 5 6 )}\end{array}$ & p-value \\
\hline Patent false lumen & $79(79 \%)$ & $48(86 \%)$ & 0.39 \\
Age (years) & $61.9 \pm 9.3$ & $59.0 \pm 13.3$ & 0.01 \\
Female & $27(27 \%)$ & $17(30 \%)$ & 0.71 \\
Hypertension & $52(52 \%)$ & $23(41 \%)$ & 0.19 \\
Thoracic aneurysm & $9(9 \%)$ & $5(9 \%)$ & 1 \\
Marfan & $7(7 \%)$ & $5(9 \%)$ & 0.67 \\
Other connective disease & $1(1 \%)$ & $1(2 \%)$ & 1 \\
BAV & $2(2 \%)$ & $2(4 \%)$ & 0.62 \\
PVD & $1(1 \%)$ & $1(2 \%)$ & 1 \\
DM & $25(25 \%)$ & $8(14 \%)$ & 0.12 \\
Hyperlipidemia & $5(5 \%)$ & $2(4 \%)$ & 1 \\
Stroke & $4(4 \%)$ & $2(4 \%)$ & 1 \\
CKD & $1(1 \%)$ & $1(2 \%)$ & 1 \\
COPD & $7(7 \%)$ & $1(2 \%)$ & 0.26 \\
CAD & $6(6 \%)$ & $1(2 \%)$ & 0.42 \\
Smoking history & $30(30 \%)$ & $14(25 \%)$ & 0.48 \\
BMI & $26.1 \pm 3.9$ & $27.1 \pm 4.5$ & 0.18 \\
Betablocker & $18(18 \%)$ & $8(14 \%)$ & 0.52 \\
ACE inhibitor & $29(30 \%)$ & $8(14 \%)$ & 0.03 \\
Systolic blood pressure & $127 \pm 35$ & $118 \pm 32$ & 0.18 \\
(mmHg) & & & \\
Diastolic blood pressure & $72 \pm 21$ & $65 \pm 17$ & 0.08 \\
(mmHg) & & & \\
\hline Vavesare & & \\
\hline
\end{tabular}

Values are expressed as numbers (\%) or mean \pm SD

$B A V$ bicuspid aortic valve, $P V D$ periferal vascular disease, $D M$ diabetes mellitus, $C K D$ chronic kidney disease, COPD chronic obstructive pulmonary disease, $C A D$ coronary artery disease, $B M I$ body mass index, $A C E$ angiotensin converting enzyme

38 patients received warfarin of which one was treated 3 months postoperatively due to biological valve prosthesis (institution protocol at the time) and all others were indefinite due to atrial fibrillation or mechanical valve prosthesis. The control group $(n=100)$ consisted of patients who did not receive anticoagulation treatment $(\mathrm{n}=45)$, received low dose aspirin $(75 \mathrm{mg})(\mathrm{n}=51)$, or received other treatments $(\mathrm{n}=4)$. Of these, one patient received aspirin and dipyridamole, one low dose low molecular weight heparin (LMWH), one aspirin and low dose LMWH, and one full dose LMWH. None of the patients on LMWH were treated longer than 3 months postoperatively. During the inclusion period, the in-hospital mortality was $13.6 \%(n=39)$ and surgical mortality (30-day or in-hospital mortality) was $13.9 \%(n=40)$ for all patients undergoing surgery for ATAAD $(n=287)$.

The perioperative patient characteristics in relation to anticoagulation therapy are presented in Tables 1 and 2 . Patients with anticoagulation treatment were younger $(59.0 \pm 13.3$ vs $61.9 \pm 9.3, p=0.01)$, less frequently treated with ACE-inhibitors preoperatively ( $14 \%$ vs $30 \%$,
Table 2 Intra- and postoperative characteristics

\begin{tabular}{|c|c|c|c|}
\hline & $\begin{array}{l}\text { No } \\
\text { anticoagulation } \\
(n=104)\end{array}$ & $\begin{array}{l}\text { Warfarin } \\
\text { or NOAC } \\
(n=52)\end{array}$ & $p$ value \\
\hline Proximal surgery & & & $<0.01$ \\
\hline Supracoronary graft & $85(85 \%)$ & 19 (34\%) & \\
\hline Bentall procedure & $9(9 \%)$ & $33(59 \%)$ & \\
\hline Mechanical & 0 & $28(54 \%)$ & \\
\hline Bioprosthesis & $9(9 \%)$ & $5(9 \%)$ & \\
\hline David/Yacoub & $4(4 \%)$ & 0 & \\
\hline $\begin{array}{l}\text { AVR and supracoronary } \\
\text { graft }\end{array}$ & $2(2 \%)$ & $4(7 \%)$ & \\
\hline Distal surgery & & & 0.55 \\
\hline Ascending aortic graft & 77 (77\%) & $46(82 \%)$ & \\
\hline Hemiarch & $15(15 \%)$ & $5(9 \%)$ & \\
\hline Arch & $8(8 \%)$ & $5(9 \%)$ & \\
\hline Crossclamp & $5(5 \%)$ & $3(5 \%)$ & 1 \\
\hline Circulatory arrest & $50(48 \%)$ & $29(56 \%)$ & 0.07 \\
\hline $\begin{array}{l}\text { Retrograde cerebral perfu- } \\
\text { sion }\end{array}$ & $42(40 \%)$ & $19(37 \%)$ & \\
\hline $\begin{array}{l}\text { Antegrade cerebral perfu- } \\
\text { sion }\end{array}$ & $11(11 \%)$ & $1(2 \%)$ & \\
\hline Primary tear excised & $62(62 \%)$ & $36(66 \%)$ & 0.67 \\
\hline GRF Glue & $65(65 \%)$ & $29(52 \%)$ & 0.11 \\
\hline CPB time (min) & $192 \pm 54$ & $218 \pm 60$ & 0.28 \\
\hline HCA time (min) & $24 \pm 10$ & $23 \pm 10$ & 0.39 \\
\hline Arterial cannulation & & & 0.11 \\
\hline Femoral & 75 (75\%) & $50(89 \%)$ & \\
\hline Subclavia & $3(3 \%)$ & $2(4 \%)$ & \\
\hline Ascending aorta or arch & 19 (19\%) & $4(7 \%)$ & \\
\hline Left ventricle & $3(3 \%)$ & 0 & \\
\hline Reop bleeding & $11(11 \%)$ & $1(2 \%)$ & 0.06 \\
\hline Plasma (units) & $4.5 \pm 4.4$ & $3.7 \pm 4.3$ & 0.32 \\
\hline Platelets (units) & $3.6 \pm 2.8$ & $3.5 \pm 2.2$ & 0.97 \\
\hline Red blood cells (units) & $5.5 \pm 5.1$ & $4.1 \pm 3.9$ & 0.07 \\
\hline Fibrinogen $^{\mathrm{a}}(\mathrm{g})$ & $5.2 \pm 3.4$ & $5.0 \pm 2.6$ & 0.79 \\
\hline Recombinant FVII (mg) & $1.8 \pm 2.4$ & $1.8 \pm 3.0$ & 0.98 \\
\hline Recombinant FVII & $23(39 \%)$ & $11(30 \%)$ & 0.39 \\
\hline Bleeding 24 h (ml) & $860 \pm 660$ & $702 \pm 306$ & 0.17 \\
\hline Massive bleeding ${ }^{b}$ & $23(23 \%)$ & $6(11 \%)$ & 0.06 \\
\hline
\end{tabular}

Values are expressed as numbers (\%) or mean $\pm \mathrm{SD}$

AVR aortic valve replacement, GRF Gelatin Resorcinol Formaldehyde, CPB cardiopulmonary bypass, HCA hypothermic circulatory arrest

a 60 missing values (38\%)

${ }^{\mathrm{b}}$ According to BART criteria

$p=0.03)$, and were more often operated with aortic root replacement procedure $(62 \%$ vs $10 \%, p<0.001)$.

Patient and operative characteristics in relation to closed (group I) or patent false lumen (group II + III) are presented in Tables 3 and 4. The use of a hemiarch procedure $(p=0.03)$ and preoperative treatment with 
Table 3 Preoperative characteristics

\begin{tabular}{|c|c|c|c|}
\hline & $\begin{array}{l}\text { Closed } \\
\text { false lumen } \\
(n=29)\end{array}$ & $\begin{array}{l}\text { Patent } \\
\text { false lumen } \\
(n=127)\end{array}$ & $p$ value \\
\hline Age (years) & $63.6 \pm 11.6$ & $60.2 \pm 10.7$ & 0.14 \\
\hline Female & $12(41 \%)$ & $32(25 \%)$ & 0.08 \\
\hline Hypertension & $15(52 \%)$ & $60(47 \%)$ & 0.70 \\
\hline Thoracic aneurysm & $3(10 \%)$ & $11(9 \%)$ & 0.73 \\
\hline Marfan & $3(10 \%)$ & $9(7 \%)$ & 0.55 \\
\hline Other connective disease & 0 & $2(2 \%)$ & \\
\hline BAV & 0 & $4(3 \%)$ & \\
\hline PVD & $1(3 \%)$ & $1(1 \%)$ & 0.34 \\
\hline DM & $8(28 \%)$ & $25(20 \%)$ & 0.35 \\
\hline Hyperlipidemia & $2(7 \%)$ & $5(4 \%)$ & 0.62 \\
\hline Stroke & 0 & $6(5 \%)$ & 0.59 \\
\hline CKD & 0 & $2(2 \%)$ & \\
\hline COPD & $4(14 \%)$ & $3(3 \%)$ & 0.04 \\
\hline CAD & $3(10 \%)$ & $4(3 \%)$ & 0.12 \\
\hline Smoking history & $7(24 \%)$ & $37(29 \%)$ & 0.57 \\
\hline BMI & $25.8 \pm 4.8$ & $27.1 \pm 4.9$ & 0.20 \\
\hline Betablocker & $9(28 \%)$ & $17(14 \%)$ & 0.02 \\
\hline ACE inhibitor & $8(28 \%)$ & $29(23 \%)$ & 0.62 \\
\hline $\begin{array}{l}\text { Systolic blood pressure } \\
(\mathrm{mmHg})\end{array}$ & $125 \pm 35$ & $124 \pm 34$ & 0.83 \\
\hline $\begin{array}{l}\text { Diastolic blood pressure } \\
(\mathrm{mmHg})\end{array}$ & $73 \pm 20$ & $69 \pm 21$ & 0.38 \\
\hline
\end{tabular}

Values are expressed as numbers (\%) or mean \pm SD

$B A V$ bicuspid aortic valve, $P V D$ periferal vascular disease, $D M$ diabetes mellitus, $C K D$ chronic kidney disease, COPD chronic obstructive pulmonary disease, $C A D$ coronary artery disease, $B M I$ body mass index, $A C E$ angiotensin converting enzyme

betablocker $(p=0.02)$ reduced the risk of patent false lumen in univariable analysis. The need for transfusion with platelets as well as fibrinogen supplement was higher in the patent false lumen group $(p=0.03$ and $p=0.01$, respectively). However, transfusion with red blood cells or plasma did not differ between groups nor did rates of reoperation for bleeding or massive bleeding.

The multivariable model presented in Table 5 showed that betablocker treatment (OR 0.24, CI 95\% 0.08-0.68, $p=0.007$ ) and hemiarch replacement (OR 0.18, CI 95\% $0.06-0.56, p=0.003$ ) were associated with a reduced risk of false lumen patency whereas platelet transfusion was an independent predictor of false lumen patency (OR 1.30, CI 95\% 1.03-1.64, $p=0.03$ ).

During follow-up, 25 patients had surgical or endovascular reinterventions. Eighteen patients underwent open thoracic surgery, 12 on the distal aorta ( 6 on the aortic arch, 7 on the descending aorta) and 11 on the proximal aorta. Eight patients had endovascular surgery, three of whom were treated with thoracic endovascular aortic repair (TEVAR) and two with fenestrated endovascular
Table 4 Intra- and postoperative characteristics

\begin{tabular}{|c|c|c|c|}
\hline & $\begin{array}{l}\text { Closed } \\
\text { false lumen } \\
(n=29)\end{array}$ & $\begin{array}{l}\text { Patent } \\
\text { false lumen } \\
(n=127)\end{array}$ & $p$ value \\
\hline Proximal surgery & & & 0.09 \\
\hline Supracoronary graft & $23(79 \%)$ & $81(64 \%)$ & \\
\hline Bentall procedure & $4(14 \%)$ & $38(30 \%)$ & \\
\hline Mechanical & $3(10 \%)$ & $25(20 \%)$ & \\
\hline Bioprosthesis & $1(3 \%)$ & $13(10 \%)$ & \\
\hline David/Yacoub & $1(3 \%)$ & $4(3 \%)$ & \\
\hline AVR and supracoronary graft & $1(3 \%)$ & $3(4 \%)$ & \\
\hline Distal surgery & & & 0.03 \\
\hline Ascending aortic graft & $19(66 \%)$ & $104(82 \%)$ & \\
\hline Hemiarch & $8(27 \%)$ & $12(9 \%)$ & \\
\hline Arch & $2(7 \%)$ & $11(9 \%)$ & \\
\hline Crossclamp & $4(9 \%)$ & $4(4 \%)$ & 0.21 \\
\hline Primary tear excised & $20(69 \%)$ & $78(62 \%)$ & 0.48 \\
\hline GRF Glue & $19(66 \%)$ & $75(59 \%)$ & 0.52 \\
\hline CPB time (min) & $191 \pm 43$ & $204 \pm 60$ & 0.28 \\
\hline HCA time (min) & $21.5 \pm 8.8$ & $23.5 \pm 11.0$ & 0.28 \\
\hline Arterial cannulation & & & 0.86 \\
\hline Femoral & $24(83 \%)$ & $101(80 \%)$ & \\
\hline Subclavia & $1(3 \%)$ & $4(3 \%)$ & \\
\hline Ascending aorta or arch & $4(14 \%)$ & $19(15 \%)$ & \\
\hline Left ventricle & 0 & $3(2 \%)$ & \\
\hline Reop bleeding & $1(3 \%)$ & $11(9 \%)$ & 0.47 \\
\hline Plasma (units) & $3.9 \pm 5.4$ & $4.3 \pm 4.1$ & 0.72 \\
\hline Platelets (units) & $2.6 \pm 2.1$ & $3.5 \pm 2.7$ & 0.03 \\
\hline Red blood cells (units) & $5.6 \pm 6.5$ & $4.8 \pm 4.3$ & 0.44 \\
\hline Fibrinogen $^{\mathrm{a}}(\mathrm{g})$ & $3.2 \pm 2.0$ & $5.4 \pm 3.2$ & 0.01 \\
\hline Recombinant FVII (mg) & $1.3 \pm 2.3$ & $1.9 \pm 2.7$ & 0.46 \\
\hline Recombinant FVII & $3(20 \%)$ & $31(38 \%)$ & 0.24 \\
\hline Bleeding 24 h (ml) & $673 \pm 370$ & $853 \pm 524$ & 0.17 \\
\hline Massive bleeding ${ }^{\mathrm{b}}$ & $5(17 \%)$ & $24(19 \%)$ & 0.84 \\
\hline \multicolumn{4}{|l|}{ Anticoagulation } \\
\hline NOAC & $4(14 \%)$ & $14(11 \%)$ & 0.75 \\
\hline Warfarin & $8(17 \%)$ & 31 (29\%) & 0.12 \\
\hline
\end{tabular}

Values are expressed as numbers (\%) or mean $\pm S D$

$A V R$ aortic valve replacement, $G R F$ gelatin resorcinol formaldehyde, $C P B$ cardiopulmonary bypass, HCA hypothermic circulatory arrest

a 60 missing values (38\%)

${ }^{\mathrm{b}}$ According to BART criteria

aortic repair (FEVAR). The remaining three patients were treated with stents in the mesenteric artery, the renal arteries, or the internal iliac artery. There were two deaths associated with these reoperations, one of whom presented with rapid dilatation of the proximal descending aorta and suspected infection or aortitis and had open arch surgery, and one of whom had been operated initially for ATAAD with a biological valve and root replacement and was later reoperated with a homograft 
Table 5 Multivariable logistic regression analysis evaluating predictors of a patent false lumen

\begin{tabular}{llll}
\hline & \multicolumn{3}{l}{ Multivariate logistic regression } \\
\cline { 2 - 4 } & OR & Cl95\% & $\boldsymbol{p}$ value \\
\hline $\begin{array}{l}\text { Betablocker } \\
\text { Distal surgery: }\end{array}$ & 0.24 & $0.08-0.68$ & 0.007 \\
Supracoronary graft & 1 & & \\
Hemiarch $^{\text {a }}$ & 0.18 & & \\
Arch $^{\text {a }}$ & 0.83 & $0.06-0.56$ & 0.003 \\
Platelets (units) $_{\text {Age }}$ & 1.30 & $0.16-4.3$ & 0.82 \\
Sex & & $1.03-1.64$ & 0.03 \\
CAD & & & ns \\
Anticoagulation & & & $\mathrm{ns}$ \\
\hline CAD cornasy arty & & & $\mathrm{ns}$ \\
\hline
\end{tabular}

CAD coronary artery disease

${ }^{\text {a }}$ Compared to supracoronary graft

due to endocarditis and a proximal descending aortic aneurysm of eight $\mathrm{cm}$ requiring replacement with a frozen elephant trunk.

The Kaplan-Meier estimates for survival in patients who were discharged and thus included in this study were $100 \%$ vs. $99 \%, 96 \%$ vs. $98 \%$, and $88 \%$ vs. $85 \%$ at 1,2 , and 5 years, respectively ( $\log \operatorname{rank} p=0.43)$ in patients with or without anticoagulant treatment (Fig. 3). Corresponding estimates for the composite endpoint of survival and freedom of reintervention were $94 \%$ vs. $96 \%, 86 \%$ vs. $90 \%$, and $76 \%$ vs. $75 \%$ at 1,2 , and 5 years, respectively (log rank $p=0.76$ ) (Fig. 4). Also, false lumen status did not have a significant impact on survival $(97 \%$ vs. $100 \%, 97 \%$ vs. $98 \%$, and $93 \%$ vs. $84 \%$ ) at 1,2 , and 5 years, respectively in patients with a patent and occluded false lumen (log rank $p=0.21$ ) (Fig. 5). Neither did the composite endpoint of survival and freedom of reintervention ( 96 vs $94 \%, 90$ vs $86 \%$ and 75 vs $76 \%$ at 1,2 , and 5 years, respectively, log rank $p=0.09$ ) (Fig. 6). Freedom from reoperation did not differ between groups (100 vs $98 \%, 95$ vs $92 \%$ and 95 vs $87 \%$ at 1,2 , and 5 years, respectively, $\log$ rank $p=0.25$ )

(Fig. 7).

\section{Discussion}

In the present study, anticoagulation treatment had no significant impact on the incidence of a false lumen patency within the first postoperative year after surgery for ATAAD. Postoperative beta-blocker treatment reduced the risk of patent false lumen, but false lumen patency was neither associated with impaired survival nor the need for reintervention.

In the current study, we hypothesized that postoperative anticoagulation therapy maintain a patent false lumen.Data in the present study showed that anticoagulation treatment was not associated with a higher incidence

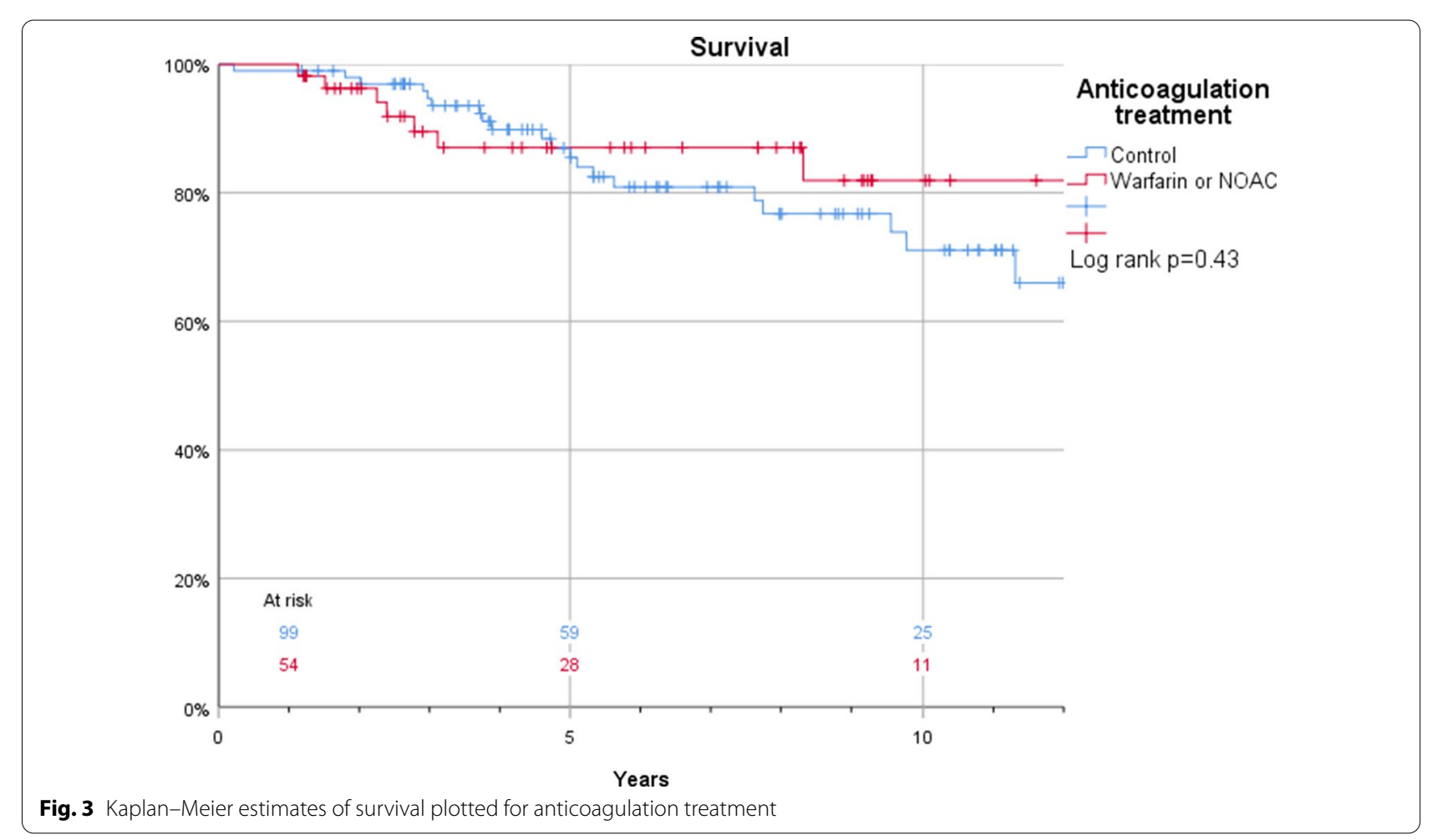




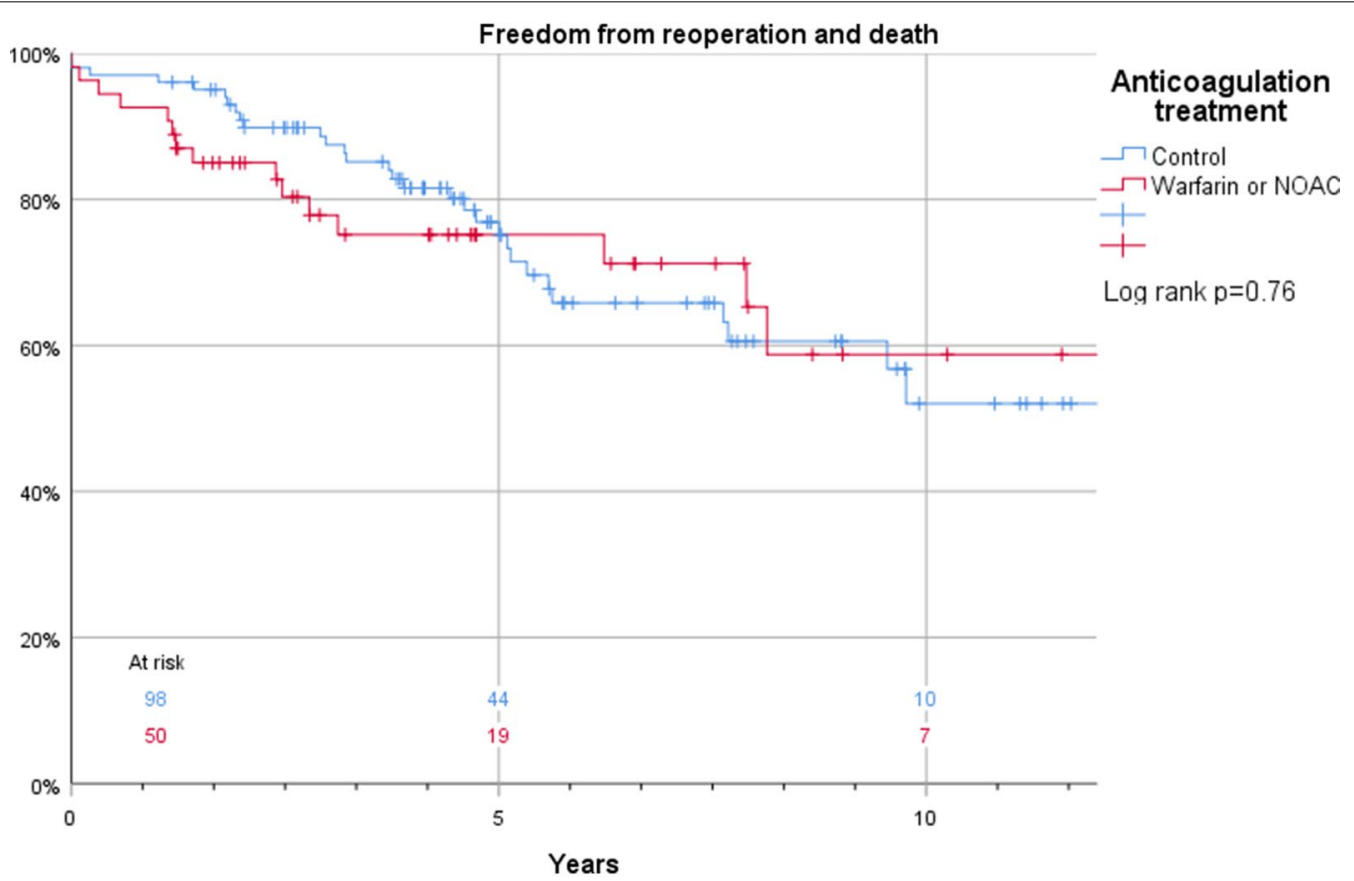

Fig. 4 Kaplan-Meier estimates of the composite endpoint of survival and freedom of reintervention plotted for anticoagulation treatment

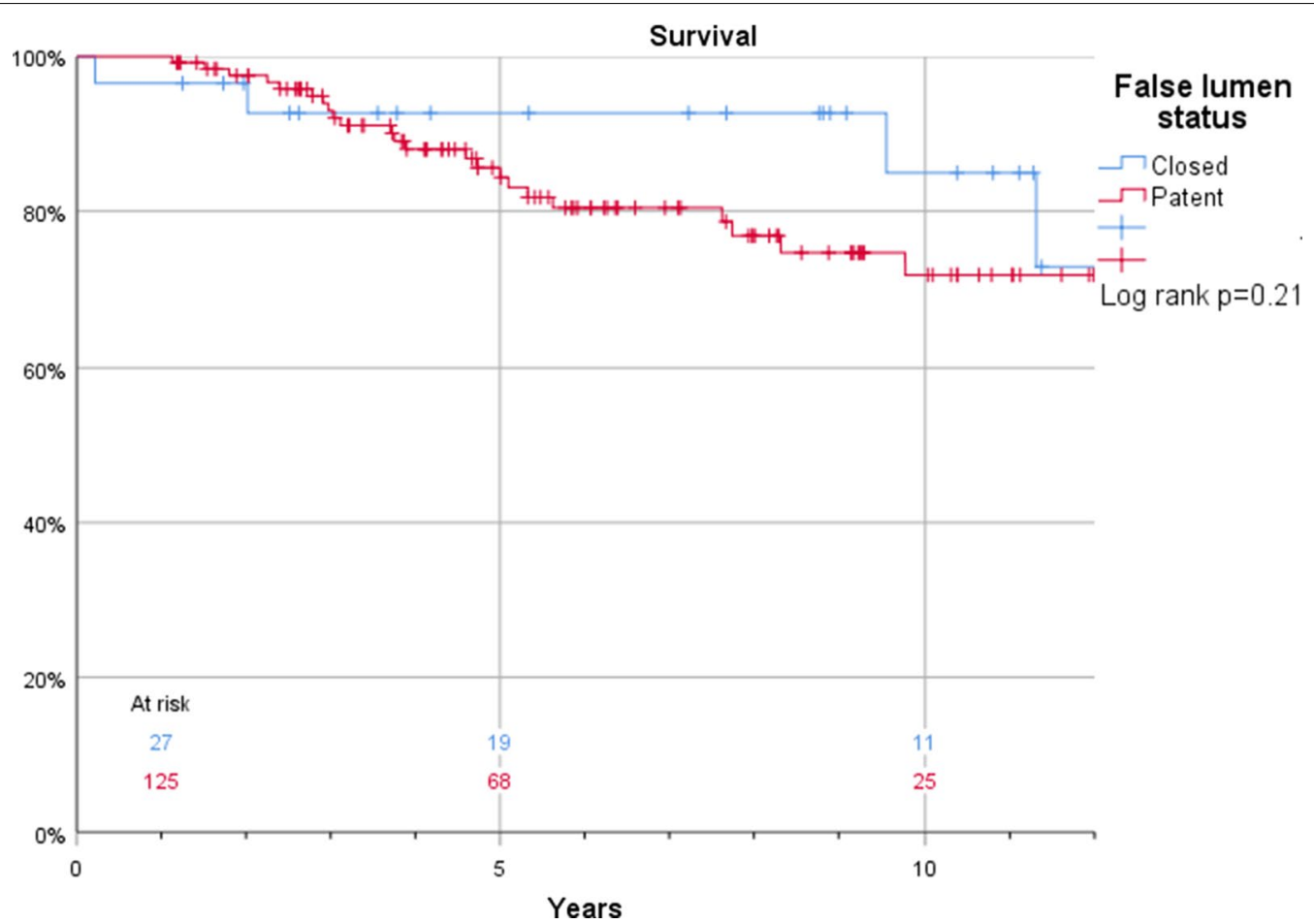

Fig. 5 Kaplan-Meier estimates of survival plotted for false lumen status 


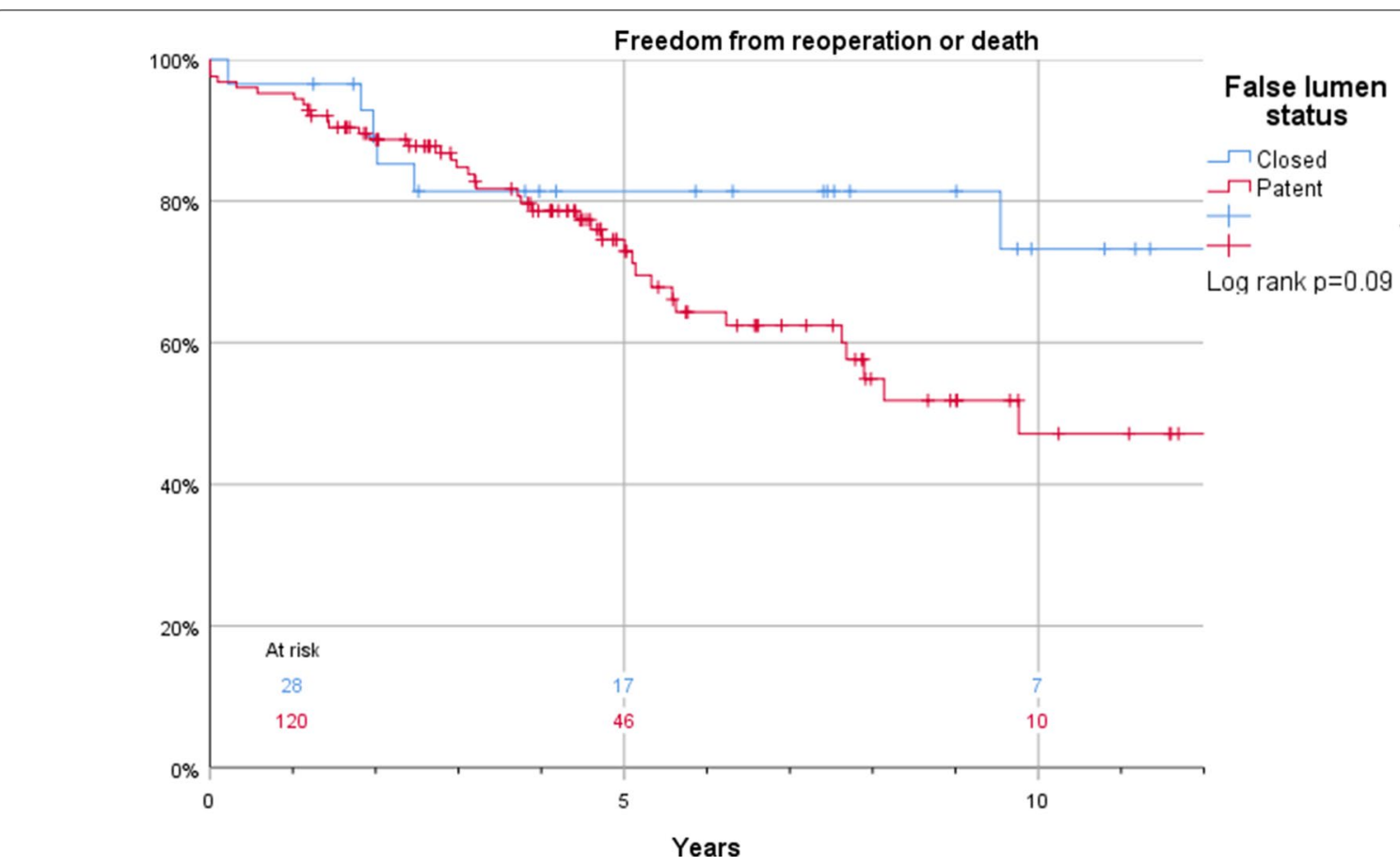

Fig. 6 Kaplan-Meier estimates of the composite endpoint of survival and freedom of reintervention plotted for false lumen status

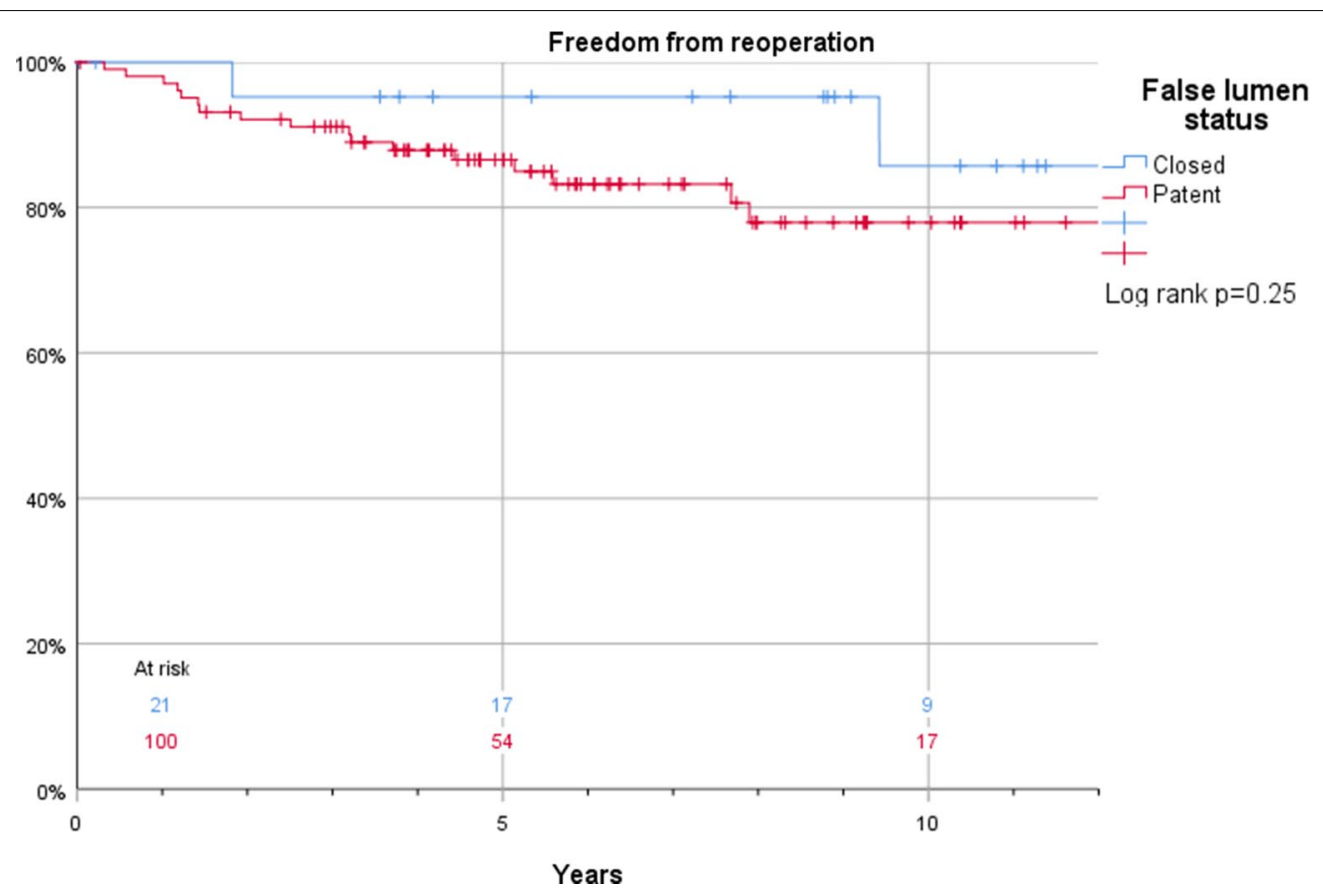

Fig. 7 Kaplan-Meier estimates of freedom from reoperation plotted for false lumen status

of patent false lumen, but in contrast to a report by Song et al. [4] who investigated 118 patients with DeBakey type I ATAAD, we could not demonstrate improved survival for patients treated with anticoagulants. In this study, patients receiving anticoagulation were younger and primarily treated with warfarin due to implantation 
of a mechanical valve in a root replacement procedure, which intuitively should result in longer life expectancy. Although there are no current recommendations regarding the use of anticoagulation following ATAAD repair, many physicians believe anticoagulation may have a negative effect on remodeling of the residual distal aorta. However, our data supports the findings of Song et al. [4] that anticoagulation is not associated with a reduced rate of false lumen thrombosis. This is further supported by the findings by von Kodolitsch et al. [8] presented in the WATAS study including 243 patients after ATAAD of which 106 patients were investigated with serial imaging. They found no difference in partial or fully patent false lumen with regards to warfarin treatment. However, Gariboldi et al. [9] investigated 147 patients with aortic dissection DeBakey type I-III of which 106 were DeBakey type I and could show a reduced probability of false lumen thrombosis if the patient received long-term oral anticoagulation (OR $0.31(\mathrm{CI} 95 \%=0.10-0.84)$ ).

The incidence of a patent false lumen during postoperative follow-up in the current study (81\%) is similar to those presented previously with figures ranging from 47 to $74 \%[4,6,11-13]$. It is possible that the low percentage of hemiarch and arch replacements in the present series (arch replacement $8 \%$, hemiarch $13 \%$ ) led to the relatively high rate of false lumen patency.

Suboptimal connection of the distal part of the graft implanted in the ascending aorta to the true lumen or the presence of secondary tears in the arch or distal aorta may account for the persistence of flow into the residual false lumen after complete surgical resection of the primary entry tear [14]. To decrease the incidence of residual patent false lumen, some authors suggest systematic extended or total arch replacement for the initial surgical management of ATAAD, irrespective of the site of entry $[15,16]$. Those supporting this method claim improved long term survival [17], while others maintain no improvement in long term survival but rather increased early mortality [18]. In this study, $40 \%$ of the patients operated with hemiarch replacement had a patent false lumen compared to $84 \%$ for patients receiving a supracoronary graft. Hemiarch replacement seems to be protective against a patent false lumen at one year (OR 0.18 , CI95\% 0.06-0.56, $p=0.003$ ), which supports the increasing trend towards this surgical technique $[15,16$, 19]. Interestingly, arch replacement did not show similar results. However, the number of patients operated with this technique in this study was small and the in-hospital mortality higher ( $21 \%$ vs $15 \%$ for arch vs ascending/ hemiarch replacement for all 283 patients with ATAAD), which is consistent with previous reports [20,21].

Hypertension is a known risk factor for developing aortic aneurysm and ATAAD, and the use of betablockers has been shown to reduce the growth rate of aortic aneurysm. This study shows that treatment with betablockers also is beneficial after surgery for ATAAD, reducing the risk of a patent false lumen (OR 0.24, CI95\% 0.08-0.68, $\mathrm{p}=0.007$ ), probably indicating the importance of strict postoperative blood pressure control.

The main hypothesis for this investigation was that anticoagulants increase postoperative false lumen patency. The reverse hypothesis could be that procoagulants reduce false lumen patency. Fibrinogen and recombinant factor VII have proved to reduce the need for transfusion in cardiac surgery $[22,23]$ but neither the use ( $p=0.19$, OR 2.48 , CI95\% 0.65-9.49) nor the administrated dose $(p=0.46$, OR 1.09 , CI95\% $0.87-1.38)$ of recombinant factor VII had a significant impact on the false lumen status.

However, we did find a significant association between fibrinogen and a higher incidence of patent false lumen $(p=0.02$, HR 1.38, CI95\% 1.07-1.79) in univariable analysis, but due to numerous missing values, fibrinogen was not included in the multivariable model. Moreover, transfusion of platelets was also increased in patients with patent false lumen (OR 1.30, CI95\% 1.03-1.64, $p=0.03$ ). These contradicting findings may merely reflect a more severe coagulopathy, requiring larger doses of procoagulant products, with the severe coagulopathy maintained by the false lumen.

Late survival in 30-day survivors was $99 \%, 87 \%$, and $74 \%$ at 1,5 , and 10 years, respectively, in this study, which is comparable to contemporary data from the NORCAAD registry [24]. Time from the index operation to reoperation has been reported to be approximately five years $[6,12]$. In the present study, both mortality and the need for surgical/endovascular treatment increased from the third year of follow-up after ATAAD in all patients with persistent patent false lumen, which suggests that structural and/or dynamic factors responsible for dissection complications require time to develop.

The present study had several limitations. The series was not that large thus increasing the risk of type II errors and biases. However, this study population was homogenous and excluded DeBakey type II ATAAD and intramural hematomas. This study was performed retrospectively, and the indications for using anticoagulation differed. Therefore, the sole effect of the drugs on the degree of thrombosis or false lumen patency after surgical repair of ATAAD may not be generalizable. The main reason for missing examinations were due to patients referred from other regions whose examinations postoperatively are not routinely made available to the investigators. Patients in need of reoperation were most likely referred to our center due to regional agreements, lowering the risk of underestimating the need for reoperation. 
Additionally, the examiner was not blinded to anticoagulation, however, a mechanical valve is not possible to blind, and the fate of the false lumen was rarely hard to determine.

During the study period of thirteen years, substantial changes in routinely imaging surveys and advances in imaging techniques improved morphological and functional assessment. Some CT examinations were performed only in the early arterial phase, which might have led to an underestimation of the actual incidence of residual patent false lumen. Moreover, enhanced CT scanning was not routinely performed in all patients who were included, and no assessment of growth rate or partial thrombosis was performed.

Although our surgical approach may have led to a relatively high incidence of residual patent false lumen, the long-term outcomes were acceptable and did not differ according to the status of the residual false lumen.

\section{Conclusion}

Anticoagulation treatment had no impact on the incidence of a false lumen over the first postoperative year. Mechanical valve is a feasible option for younger patients and anticoagulation for atrial fibrillation may be used with no regard to false lumen patency in surgery for ATAAD. Hemiarch replacement seems to be favorable in reducing the rate of a patent false lumen and support the current opinion that this should be the gold standard for ATAAD repair [25, 26]. Nevertheless, a careful follow-up after surgery for ATAAD is still necessary for all patients.

\footnotetext{
Abbreviations

ATAAD: Acute type A aortic dissection; CT: Computed tomography; PACS: Picture archiving and communication system; $\mathrm{IH}$ : Intramural hematoma; $\mathrm{HU}$ : Hounsfield unit; NOAC: Non vitamin-K antagonist oral anticoagulant; IQR: Interquartile range; HR: Hazard ratio; OR: Odds ratio; Cl: Confidence interval; LMWH: Low molecular weight heparin; ACE: Angiotensin converting enzyme; TEVAR: Thoracic endovascular aortic repair; FEVAR: Fenestrated endovascular aortic repair.
}

\section{Acknowledgements}

None.

\section{Authors' contributions}

Conception and design: ML, SN, IZ, GB, JS. Administrative support: SN, JS. Provision of study materials or patients: ML, GB, IZ. Collection and assembly of data: ML, GB, IZ, Sigurdur Ragnarsson. Data analysis and interpretation: ML, IZ, SN. Manuscript writing: All authors. All authors read and approved the final manuscript.

\section{Funding}

Open access funding provided by Lund University.

\section{Availability of data and materials}

Data not available for review due to limitations in ethics approval.

\section{Declarations}

Ethics approval and consent to participate

The registry was approved by the regional ethical review board, and a waiver of informed consent for the retrospective review of medical records was granted for the registry (ref. 2015/197).

\section{Consent for publication}

Not applicable.

\section{Competing interests}

All authors declare that they have no competing interests.

\section{Author details}

${ }^{1}$ Department of Clinical Sciences Lund, Cardiothoracic Surgery, Lund University and Skåne University Hospital, Getingevägen 4, 22185 Lund, Sweden. ${ }^{2}$ Department of Medical Imaging and Clinical Physiology, Lund University and Skåne University Hospital, Lund, Sweden.

Received: 13 December 2020 Accepted: 19 September 2021

Published online: 28 September 2021

\section{References}

1. Bernard $Y$, et al. False lumen patency as a predictor of late outcome in aortic dissection. Am J Cardiol. 2001;87(12):1378-82.

2. Erbel $\mathrm{R}$, et al. Effect of medical and surgical therapy on aortic dissection evaluated by transesophageal echocardiography. Implications for prognosis and therapy. The European Cooperative Study Group on Echocardiography. Circulation. 1993;87(5):1604-15.

3. Pretre R, Von Segesser LK. Aortic dissection. Lancet. 1997;349(9063):1461-4

4. Song SW, et al. Effects of early anticoagulation on the degree of thrombosis After repair of acute DeBakey type I aortic dissection. Ann Thorac Surg. 2011;92(4):1367-74 (discussion 1374-5).

5. von Kodolitsch Y, et al. Warfarin anticoagulation in acute type A aortic dissection survivors (WATAS). Cardiovasc Diagn Ther. 2017;7(6):559-71.

6. Gariboldi V, et al. Long-term outcomes after repaired acute type A aortic dissections. Interact Cardiovasc Thorac Surg. 2007;6(1):47-51.

7. Castaner $\mathrm{E}$, et al. CT in nontraumatic acute thoracic aortic disease: typical and atypical features and complications. Radiographics. 2003;23:593-110.

8. LePage MA, et al. Aortic dissection: CT features that distinguish true lumen from false lumen. AJR Am J Roentgenol. 2001;177(1):207-11.

9. Holloway BJ, Rosewarne D, Jones RG. Imaging of thoracic aortic disease. Br J Radiol. 2011;84:S338-54.

10. Zindovic l, et al. Impact of hemodynamic instability and organ malperfusion in elderly surgical patients treated for acute Type A aortic dissection. J Card Surg. 2015;30(11):822-9.

11. Ergin MA, et al. Significance of distal false lumen after type A dissection repair. Ann Thorac Surg. 1994;57(4):820-4 (discussion 825).

12. Kimura, N., et al., Influence of patent false lumen on long-term outcome after surgery for acute type A aortic dissection. J Thorac Cardiovasc Surg, 2008. 136(5): 1160-6, 1166 e1-3.

13. Sakaguchi $\mathrm{G}$, et al. Patency of distal false lumen in acute dissection: extent of resection and prognosis. Interact Cardiovasc Thorac Surg. 2007:6(2):204-7.

14. Evangelista A, et al. Long-term outcome of aortic dissection with patent false lumen: predictive role of entry tear size and location. Circulation. 2012;125(25):3133-41.

15. Hirotani T, et al. Routine extended graft replacement for an acute type A aortic dissection and the patency of the residual false channel. Ann Thorac Surg. 2003;76(6):1957-61.

16. Takahara Y, et al. Total aortic arch grafting for acute type A dissection: analysis of residual false lumen. Ann Thorac Surg. 2002;73(2):450-4.

17. Uchida $\mathrm{N}$, et al. Operative strategy for acute type a aortic dissection: ascending aortic or hemiarch versus total arch replacement with frozen elephant trunk. Ann Thorac Surg. 2009;87(3):773-7. 
18. Colli A, et al. Acute DeBakey Type I aortic dissection without intimal tear in the arch: is total arch replacement the right choice? Interact Cardiovasc Thorac Surg. 2018;26(1):84-90.

19. Di Bartolomeo R, et al. When and how to replace the aortic arch for type A dissection. Ann Cardiothorac Surg. 2016;5(4):383-8.

20. Ohtsubo $S$, et al. Surgical results of hemiarch replacement for acute type A dissection. Ann Thorac Surg. 2002;74(5):S1853-6 (discussion S1857-63)

21. Kim JB, et al. Total arch repair versus hemiarch repair in the management of acute DeBakey type I aortic dissection. Eur J Cardiothorac Surg. 2011;40(4):881-7.

22. Brase J, et al. Analysis of outcomes using low-dose and early administration of recombinant activated factor VII in cardiac surgery. Ann Thorac Surg. 2016;102(1):35-40

23. Li JY, et al. Fibrinogen concentrate in cardiovascular surgery: a meta-analysis of randomized controlled trials. Anesth Analg. 2018;127(3):612-21.
24. Olsson C, et al. Medium-term survival after surgery for acute Type A aortic dissection is improving. Eur J Cardiothorac Surg. 2017;52(5):852-7.

25. Poon SS, et al. Hemiarch versus total aortic arch replacement in acute type A dissection: a systematic review and meta-analysis. Ann Cardiothorac Surg. 2016;5(3):156-73.

26. Lansman SL, et al. Extended arch procedures for acute Type A aortic dissection: A Downstream Problem? Semin Thorac Cardiovasc Surg. 2019;31(1):17-20

\section{Publisher's Note}

Springer Nature remains neutral with regard to jurisdictional claims in published maps and institutional affiliations.
Ready to submit your research? Choose BMC and benefit from:

- fast, convenient online submission

- thorough peer review by experienced researchers in your field

- rapid publication on acceptance

- support for research data, including large and complex data types

- gold Open Access which fosters wider collaboration and increased citations

- maximum visibility for your research: over $100 \mathrm{M}$ website views per year

At BMC, research is always in progress.

Learn more biomedcentral.com/submissions 